\title{
Encontro terapêutico ou processo-metamorfose: desafio dos serviços territoriais e comunitários
}

Therapeutic encounter or process-metamorphosis: the challenge of territorial and
community services

Fernando Sfair Kinker ${ }^{1}$

RESUMO Este artigo traz uma reflexão sobre a questão do cuidado nos serviços territoriais e comunitários, no contexto de consolidação e aperfeiçoamento do SUS. Através da noção de encontro terapêutico, busca afirmar a necessidade de os processos terapêuticos partirem do diálogo e das mudanças nos fluxos de poder entre usuário e terapeuta, produzindo percursos singulares e inéditos não previstos. Através da ideia de que o processo de transformação é a regra e não a exceção nos organismos vivos, constata que a modificação do terapeuta é condição para a modificação do usuário dos serviços.

PALAVRAS CHAVE: Serviços territoriais e comunitários; Relação terapêutica; Relações de poder.

ABSTRACT This paper presents a reflection about the question of the carefulness in the territorial and communitarian services, in the context of SUS's consolidation and improvement. Through the notion of therapeutic meeting, it aims to affirm the need of the therapeutic process to arise from dialogue and changes in the power flow between the therapist and the patient, creating singular and unique ways not predicted before. Through the Idea that in living organism the transformation process is the rule and not the exception, it is ascertained that the therapist's modification is a condition for modifying the patient.

KEYWORDS: Territorial and community services; Therapeutic relationship; Power relations. 


\section{Introdução}

Este artigo é fruto da experiência de trabalho em serviços territoriais e comunitários, da prática de supervisão institucional em vários CAPS e de discussóes elaboradas na prática da graduação e da pesquisa com alunos e docentes da universidade. Ele tem como objetivo trazer uma reflexão sobre a questão do cuidado nos serviços territoriais e comunitários, no contexto de consolidação e aperfeiçoamento do SUS. Embora ele trate mais precisamente da questáo dos serviços de saúde mental, a maior parte dos dilemas aqui apresentados pode ser estendida à realidade dos demais serviços de saúde, da Atenção Básica aos serviços de média e alta complexidade.

Como ficará claro nos parágrafos que se seguem, o processo de diálogo com os usuários dos serviços e o processo de transformação das condiçóes de saúde serão aqui designados como "encontro terapêutico" e "processo-metamorfose", ao invés de termos mais frequentemente utilizados como o de tratamento ou mesmo o de clínica. Isso porque se parte do princípio de que o conceito de terapêutica pode ultrapassar a ideia de tratamento. A origem etimológica da palavra terapêutica faz uma referência à questão do tratamento e da cura, mas ela também pode ser usada na perspectiva do cuidar, mais no sentido de uma intervenção que transforma os atores em jogo do que na perspectiva transcendente de obtenção de uma cura ou de um estado pré-concebido a que se quer chegar. Alguns conceitos mais tradicionais ligados à ideia de cura são insuficientes para expressar os processos complexos de transformação dos sujeitos, que envolvem essencialmente relaçóes de poder. Ao invés de relaçóes terapêuticas, poderíamos muito bem utilizar o termo relaçôes de poder.

\section{Nós e os outros: princípios de organização}

São os novos conhecimentos biológicos, físicos e cósmicos que nos indicam que o humano não é apenas o resultado de uma evolução biológica. De um lado, ele traz consigo as irmás-máes dos primeiros seres celulares, surgidos talvez há três bilhóes de anos; do outro, suas células são constituidas de macromoléculas, constituidas de átomos, entre eles o carbono, ele próprio produzido pela colusão entre três núcleos de hélio num Sol anterior ao nosso; e as particulas constitutivas desses átomos nasceram nos primórdios do Universo. Isso significa que, em nossa singularidade humana, trazemos conosco toda a história do Universo, com suas características fisicas, quimicas, biológicas. Somos filhos do Universo. Mas, ao mesmo tempo, somos separados por nossa cultura, nossa mente e nossa consciência. (MORIN, 2010, p. 207).

O princípio de organização que nos traz Morin serve para enfatizar que pertencemos a uma mesma natureza das coisas inanimadas, e que a regra é a possibilidade de transformação que pode gerar novas organizaçóes, novos organismos vivos, sempre auto-ecoorganizados (MORIN, 1996):

\section{[...] 'a auto-organização significa obviamente autonomia, mas um sistema auto-organizador é um sistema que deve trabalhar para construir e reconstruir sua autonomia e que, portanto, dilapida energia. Em virtude do segundo prin- cípio da termodinâmica, é necessário que este sistema extraia energia do exterior; isto é, para ser autônomo, é necessário depender do mundo externo. E sabemos, pelo que podemos observar, que esta dependência não é só energética, mas também informativa, pois o ser vivo extrai in- formação do mundo exterior a fim de organizar seu comportamento. (MORIN, 1996,p. 46).}

A ideia espinosiana de natureza ou deus, como uma totalidade da qual todos os seres fazem parte, pode aqui ser somada à necessária interdependência que os organismos têm do mundo exterior. O conceito de Deus ou natureza, em Spinoza (2009), aponta para o pertencimento comum de todas as coisas; se o corpo e a mente humana são expressôes de uma mesma substância, os humanos e os outros seres são manifestaçôes divinas da mesma natureza. Entâo, temos Deus ou a 
natureza em nossas veias. Nesse sentido,só podemos exercer nossa autonomia e auto-organização através do diálogo permanente com o ambiente, e, portanto, somos ao mesmo tempo nós próprios e os outros.

No decorrer do processo evolutivo, a metamorfose, que tem produzido sempre novas organizaçóes, tem sido a regra e não a exceção, se pensarmos em um tempo mais longo da história do universo. Sendo assim, a saúde pode ser considerada esse processo-metamorfose, que transforma o organismo constantemente, e que aumenta sua potência de agir (SPINOZA, 2009). Como ressalta Spinoza (2009), os afetos podem aumentar ou diminuir a potência de agir, e o Conatus, o esforço para perseverar na existência, busca as formas de aumentar nossa potência de agir, pois dela depende a vida. $\mathrm{O}$ propósito da intervenção terapêutica seria, assim, ampliar as possibilidades de existência e de transformação, enriquecendo a existência através desse processo-metamorfose.

\section{O cotidiano dos serviços na prática metamorfósica}

Consideremos os serviços territoriais e comunitários para pensar na prática do cuidado, e tenhamos os CAPS (Centros de Atenção Psicossocial) como referência que permita a extensão dessas reflexóes para os demais serviços do SUS.

Como é sabido, os CAPS são serviços que devem se responsabilizar pelas questóes de saúde mental de determinada área de abrangência, devendo oferecer um cuidado contínuo no tempo a partir de um intenso diálogo com seus usuários (BRASIL, 2004).

No cotidiano de trabalho dos CAPS, o diálogo com os usuários é central. A forma como se dá esse encontro é que vai determinar o percurso terapêutico, as demandas, os desafios e os projetos a construir. $\mathrm{E}$ como se dá esse diálogo? Como acessar as reais necessidades dos usuários (BASAGLIA, 1977; BASAGLIA, BASAGLIA, 1985) sem reproduzir as respostas já préformadas pelos paradigmas psiquiátricos, psicológicos ou sociológicos, baseadas em necessidades artificiais produzidas pelas ideologias científicas? Como nos diz
Basaglia, a psiquiatria só se relaciona com a doença e não com o sujeito, e para isso tem respostas prontas, construídas sobre a nosografia, sem dar espaço para que as perguntas, as necessidades reais e a experiência existencial do doente apareçam:

Liberar as necessidades reais do usuário de um serviço, das necessidades artificiais, produzidas de tal maneira que a resposta à necessidade se traduza no controle da classe subordinada, significa romper esse mecanismo e fazer explícita, na prática, a função da ideologia científica como suporte falsamente neutro da ideologia dominante. (BASAGLIA; BASAGLIA, 1977,p. 17, tradução nossa).

Um movimento de colocar em suspensão os conhecimentos e repertórios técnicos parece aqui representar uma forma importante de viabilizar um encontro transformador com os usuários dos serviços. Colocar em suspenso, num cabide imaginário, os conhecimentos e os modos de operação aprendidos, serve como estratégia para produzir uma nova escuta e uma nova realidade. Considerando que a realidade traduzida por nós não é uma fotografia ou um espelho exato do que está fora de nós, pois 'o objeto do conhecimento é coproduzido por nossas projeçóes mentais sobre uma realidade exterior e pela introdução, via tradução e reconstrução, dessa realidade exterior em nossa mente' (MORIN, 2010, p. 243-244), podemos entender que, se modificarmos as respostas, modificaremos as demandas, produzindo uma outra realidade; se modificarmos os efeitos, modificaremos as causas através do principio da recursividade (MORIN, 2010). O princípio da recursividade é aquele em que causa e efeito se entrelaçam; um efeito retroage sobre sua própria causa, produzindo movimentos não-lineares e bifurcantes. O conhecimento, as formas de traduzir, enquadrar, interpretar, produzir a realidade, pode ser utilizado por nós se não nos submetermos a ele, se não deixarmos que ele nos domine. Porque as respostas que damos coproduzem os fenômenos: 
[...] los millones de hombres y mujeres cuya producción de sentido está limitada, bloqueada, aniquilada, negada, no están em dicha condición por ser enfermos mentales o por estar en terribles situaciones de sufrimiento psicosocial, sino essencialmente por falta de respuesta adecuada a sus enfermedades o a sus sufrimientos psicosociales. En otras palabras, no es la discapacidad resultante de condiciones de enfermedad o de sufrimiento psicosocial la que quita sentido a los seres humanos sino una decisión discriminatória tomada por otros. Una decisión que define la producción de sentidos ajenos a la razón dominante como 'ausencia de sentido'. (SARACENO, s.d., p. 11-12).

Desta forma, podemos entender que os conceitos de saúde e de doença vão definir o fenômeno a ser tratado, e que podemos também, por exemplo, compartilhar de um conceito de saúde como intensidade de vida, em que o considerado doente pode ter mais saúde que os ditos normais, por ter mais intensidade de vida em algumas ocasiōes. A grande saúde de Nietzsche (1998, 2003, 2008) ou o aumento da potência de agir (SPINOZA, 2009) podem ser uns dos muitos referenciais a serem utilizados. E, nesse sentido, o projeto terapêutico, o projeto do cuidar, pode se constituir na produção de um projeto de vida. Como sugere Nicácio (2003), a construção dos projetos de vida e o processo terapêutico seriam a construção permanente de um itinerário de inclusão que parte dos trajetos singulares dos usuários, tendo como lócus da intervenção a vida concreta dos mesmos, suas relaçóes, seus modos de vida. Escapar-seia, entâo, de uma abordagem focada na doença, colocando-a entre parênteses para lidar com o sujeito e suas reais necessidades (BASAGLIA, 1985). Tal abordagem, fruto do encontro primeiro entre usuários e terapeutas, exigiria, então, uma mútua transformação, o que nos levaria à ideia contraditória de que a transformação do usuário dependeria da transformação do profissional. Ou seja, a transformação do profissional seria a condição primeira e um sinal de que o usuário estaria se transformando, aumentando sua potência de agir. As mudanças nos fluxos das relaçóes de poder seriam, então, o arsenal de fundo das mudanças terapêuticas, já que as relações poder/saber produzem as realidades e os conhecimentos, as terapias e os contexto de vida. É por esse motivo que as relaçôes terapêuticas são essencialmente relações de poder: são construções de realidades compartilhadas ou não por atores que confrontam seus saberes e formas de entender o mundo; a busca por uma construção compartilhada de realidade. Como sugere Nathan (1996), a relação terapêutica engendra um debate teórico entre formas diversas de ver o mundo; a teoria do terapeuta e a do paciente se confrontam num sistema de comunicação singular. A sintonia fina que permite uma comunicação na mesma faixa de frequência entre usuário e terapeuta é o grande desafio da intervenção terapêutica, sendo o confronto da potência de agir de ambos a energia que produz as realidades. O que está em jogo nessas relaçôes são determinadas produçóes de verdade, estabelecidas a partir de saberes diversos, entre os atores envolvidos. Caberia ao terapeuta e ao paciente estabelecer um diálogo múltiplo que produzisse realidades flexíveis e maleáveis, que se movimentassem. Ou seja, produzir na relação terapêutica processos de transformação das condiçốes de vida, dos papéis sociais, de produção de novos conhecimentos, novos valores e, assim, novas realidades múltiplas e enriquecedoras, portanto, potentes. $O$ sofrimento singular possui uma dimensão estritamente relacional, que o coproduz. Assim, produzimos os percursos que a experiência do sofrimento vai tomar, fazendo-os em conjunto com a pessoa que sofre.

Outro desafio colocado por esse pleno encontro dos usuários com os profissionais dos serviços (sejam estes CAPS, UBS/USF) seria ter como palco das açóes terapêuticas o contexto real de vida dos usuários: um território vivo de relações, onde se misturam percursos coletivos e singulares, relaçôes, produçôes sociais, sofrimento ou saúde. E, nesses termos, a complexa aparência do território coloca desafios importantes aos profissionais dos serviços territoriais. Tal aparência complexa é composta por uma série de características que lhe confere um ar impenetrável e perigoso: o suposto, mas falso, vazio de recursos; a violência; a fragilidade dos laços sociais provocados pelos novos desenraizamentos do atual estágio do capitalismo; a desregulamentação 
das relaçóes de trabalho e das demais relações (BAUMAN, 2003); o controle exercido através da sensação de incerteza quanto ao amanhã; as novas formas de controle dos desvios que combinam medidas duras e disciplinares típicas de uma sociedade disciplinar (FOUCAULT, 2000, 2005) com as estratégias flexíveis de uma sociedade do controle (DELEUZE, 1992), que se baseiam num misto de submissão voluntária e captura involuntária com vigilância permanente e capilarizada.

Enfim, o trabalho territorial exige uma imersão nos contextos concretos de vida, que pode ser evitado pela manutenção constante de programas de atividades protocolares que afastam o contato com as contradiçóes sociais e com a realidade de vida dos usuários (as grades de atividade préformadas por oficinas terapêuticas, grupos terapêuticos, atendimentos individuais e grupais que reproduzem o distanciamento das contradiçôes cristalizam os papéis e as situaçôes, evitando qualquer metamorfose e produção de saúde). É óbvio que não se trata de negar a potencialidade dos procedimentos dos serviços de saúde mental, mas de constatar que esses procedimentos, afastados da realidade concreta de vida dos usuários em seu território de existência, servem apenas como formas de controle dos desvios e de manutenção da ordem, empobrecimento da existência de usuários e profissionais, produzindo o que Saraceno chamaria de entretenimento (SARACENO, 1999), ou seja, ocupar o tempo dos usuários dos serviços como um fim em si mesmo, sem provocar mudanças nas relaçôes sociais, exercendo de fato uma forma de controle e de invalidação. Poderíamos trocar o termo entretenimento pelo de controle e invalidação, lembrando que passar o tempo como um fim em si mesmo, no manicômio ou no CAPS, mesmo que desenvolvendo toda a sorte de atividades, pode tanto ser algo prazeroso como doloroso, que resulta em despotencializaçóes, se não estiver conectado e dialogando com a realidade concreta de vida dos usuários, onde estão as contradiçóes e as potências de transformação (SARACENO, 1999,p. 16-17).

\section{Como o diálogo com os usuários pode modular o cotidiano dos serviços}

Parecem ser necessárias uma grande dose de liberdade e a possibilidade de experimentação para produzir situaçóes que sejam transformadoras. A forma de organização dos serviços expressa o grau de possibilidades de diálogo com os usuários. Por exemplo: se o acesso é facilitado, se a forma de acolher é burocratizada ou não, se há mecanismos que barram e dificultam a entrada dos usuários nos serviços; se as equipes são flexíveis e têm prontidão (KINOSHITA, 1996), ou se estão presas em protocolos rígidos; se, no contato com o território, são agenciados e potencializados novos recursos intersetoriais que envolvem relaçóes com outros atores de fora do campo da saúde mental; se os projetos terapêuticos são vistos como projetos mobilizadores de vida ou se são empregados como protocolos de atendimento, muitas vezes apresentados em fichas que, longe de representarem a amplitude necessária dos caminhos a seguir, são limitadores e inibidores da experimentação (afinal, um projeto terapêutico como projeto de vida é o próprio processo de encontro e de negociação entre terapeutas e usuários, um movimento que não cabe em nenhuma ficha, embora os instrumentos de registro possam ajudar, em algum momento, na organização das estratégias sempre diferentes de intervenção); se a unidade garante o Direito ao asilo (KINOSHITA, 1996). Como nos diz Kinoshita (1996,p. 44),

\section{[...] nas situaçôes em que o paciente neces- site de proteção elou continência, entende- mos que o sistema deve garantir espaços que proporcionem um distanciamento adequado das condiçóes habituais de vida do paciente (meio familiar, ambiente de trabalho, círculo de amizades). Distanciamento que não deve significar isolamento nem reclusáo... Nas si- tuaçôes mais críticas muitas vezes é necessá- rio criar uma distância útil, que permita a percepção diferenciada da situação, seja pelo paciente, seja por todos aqueles envolvidos. (familiares, amigos, patrōes).}

Muda-se, com isso, a noção de internação, que deixa de ser uma forma de controle e o tratamento em si para ser uma ação estratégica no acompanhamento dos usuários, viabilizada através de negociaçóes 
que são mantidas permanentemente no tempo, e não apenas no momento em que a pessoa precisa desse distanciamento.

Além da forma de organização dos serviços, a postura dos profissionais e dos usuários determinará formas novas de encontro. Um dos encontros possíveis é aquele que a participação em reunióes e eventos do movimento da luta antimanicomial, ou em fóruns de discussão e decisão, possibilita. Tais encontros, como lugares, por excelência, de despojamento de papéis, já que neles usuários e trabalhadores se identificam na condição de militantes, costumam ser umas das situaçôes mais terapêuticas existentes, exatamente porque os fluxos de poder rodopiam, todos saem de seus antigos lugares, o objeto a se debruçar deixa de ser os problemas da doença para ser os projetos coletivos a serem construídos. O termo projeto indica o protagonismo e a projetualidade que caracterizam qualquer processo de transformação. Desconstruir o paradigma psiquiátrico faz parte da estratégia de construção de novas formas de sociabilidade. Projetos como coletivos, que visam ao cuidado de outros coletivos. Participar de um projeto que cuide de pessoas (seja prestando serviços, mensagens ou oferecendo objetos de qualidade para o uso) ou de vários projetos significa não se submeter a uma identidade fixa e exclusiva, mas navegar pela maior parte dos espaços proibidos e privados, no sentido de enriquecer a existência. Lidar com singularidades e não com identidades. Essa ideia reforça a oportunidade de se construírem sujeitos coletivos, que possam, em sincronia, desenvolver projetos capazes de garantir bem-estar e liberdade para todos no uso de suas capacidades criativas.

$\mathrm{Na}$ verdade, o que está por trás da relação terapeuta-usuário, serviços-usuários, é aquilo que promoveu o nascimento da psiquiatria e de todas as demais instituiçóes da sociedade disciplinar: novas formas de sociabilidade, pautadas na mercadoria e tendo como centro operador o trabalho. Daí a necessidade de questionarmos não só a relação entre a psiquiatria e a sociedade do trabalho, mas, sobretudo, a própria sociedade do trabalho, pensando que também uma nova vida social, que não tenha o trabalho como centralidade, faz-se possível e desejável.

\section{Concluindo}

Para finalizar, podemos mais uma vez constatar que o grande desafio do encontro terapêutico-metamorfósico com os usuários é realizar uma verdadeira ruptura epistemológica; aquela que transforma radicalmente o objeto da psiquiatria, e que parecemos estar ainda longe de realizar. Trata-se da ruptura proposta por Rotelli (1990), quando refere que a desinstitucionalização é um processo de transformação cultural, prática, legal, onde o objeto da psiquiatria deixa de ser a doença, passando a ser

\section{[...] 'a existência-sofrimento dos pacientes e sua relação com o corpo social'. O mal obscuro da psiquiatria está em haver constituido insti- tuiçôes sobre a separação de um objeto fictício - a doença - da existência global, complexa e concreta do paciente e do corpo da sociedade.} (ROTELLI, 1990, p. 90).

É necessário superar as noçóes de tratamento, cura, eliminação de sintomas, para adentrar no campo da produção de vida, que exige a transformação dos modos de vida, das formas de sociabilidade e dos valores. É necessário um pouco de humildade para que a ciência cartesiana admita sua insuficiência, abrindo-se ao diálogo com outros campos do conhecimento há muito desprezados. Para uma existência rica, são necessários a multiplicidade de experiências e o descarte da simplificação dos fenômenos, adotando uma perspectiva complexa (Morin), que considere a vida em sua totalidade.

Essa necessária ruptura com o paradigma tradicional estaria ligada à passagem da pesquisa causal à reconstrução de uma concatenação possibilidade-probabilidade (ROTELLI, DE LEONARDIS, MAURI, 1990, p. 30). Nessa perspectiva, superar o paradigma racionalista problema-solução representaria propor novas formas de cuidado.

Uma nova concepção de cuidado pode, então, entrar finalmente em cena:

Concretamente se transformam os modos nos quais as pessoas são tratadas (ou não tratadas) 
para transformar o seu sofrimento, porque a terapia não é mais entendida como a perseguição da solução-cura, mas como um conjunto complexo, e também cotidiano e elementar, de estratégias indiretas e mediatas que enfrentam o problema em questão através de um percurso crítico sobre os modos de ser do próprio tratamento (ROTELLI, DE LEONARDIS,
MAURI, 1990, p. 29). ... cuidar significa ocupar-se, aqui e agora, de fazer com que se transformem os modos de viver e sentir o sofrimento do "paciente" e que, ao mesmo tempo, se transforme sua vida concreta e cotidiana, que alimenta este sofrimento. (ROTELLI, DE LEONARDIS, MAURI, 1990, p. 33).

\section{Referências}

BASAGLIA, F. As instituições da violência. In: BASAGLIA, F. (org.). A instituição negada. Rio de Janeiro: Graal, 1985. p. 99-133.

BASAGLIA, F.; BASAGLIA, F. O. Los crímenes de la paz. In: BASAGLIA, F.; BASAGLIA, F. O. (Org.). Los crímenes de la paz: Investigación sobre los intelectuales y los técnicos como servidores de la opresión. Madrid: Siglo Veintiuno de España Editores, 1977. p. 13-102.

BRASIL. Portaria GM n. 336, de 19 de fevereiro de 2002. Legislação em Saúde Mental. 1990-2004.5. ed. ampl. Brasília: Ministério da Saúde, 2004. (Série E. Legislação de Saúde). 9 p.

FOUCAULT, M. Vigiar e punir. 23. ed. Petrópolis: Vozes, 2000. 263 p. História da loucura na idade clássica. 8. ed. São Paulo: Perspectiva, 2005. 559 p. (Coleção Estudos 61)

DELEUZE, G. Conversações. São Paulo: 34 Letras, 1992. 232 p.

KINOSHITA, R. T. Em busca da cidadania: desinstitucionalização de um hospital psiquiátrico. In: BRAGA CAMPOS, F. C.; HENRIQUES, C. M. P. (orgs.). Contra a maré à beira-mar: a experiência do SUS em Santos. São Paulo: Scritta, 1996. p. 39-49.

MORIN, E. A noção de sujeito. In: SCHNITMAN, D. F. (Org.). Novos paradigmas, cultura e subjetividade. Porto Alegre: Artes Médicas, 1996. p. 45-58.

Meu caminho. Rio de Janeiro: Bertrand Brasil, 2010. p. 189-

567.

NIETZSCHE, F. Genealogia da moral: uma polêmica. São Paulo: Companhia das Letras, 1998. 176p.
Assim falava Zaratustra: um livro para todos e para ninguém. 12. ed. Rio de Janeiro: Civilização brasileira, 2003. 536p.

A vontade de poder. Rio de Janeiro: Contraponto, 2008.

$516 p$.

NICACIO, M. F. S. Utopia da realidade: contribuições da desinstitucionalização para a invenção de serviços de saúde mental. 2003. 205f. Tese (Doutorado) - Faculdade de Ciências Médicas, Universidade Estadual de Campinas, Campinas, 2003.

ROTELLI, F. A instituição inventada. In: NICÁCIO, M. F. S. (Org.). Desinstitucionalização. São Paulo: Hucitec, 1990. p. 89-100.

ROTELLI, F.; DE LEONARDIS, O.; MAURI, D. Desinstitucionalização, uma outra via: A reforma psiquiátrica italiana no contexto da Europa Ocidental e dos "Países Avançados". In: NICÁCIO, M. F. S. (Org.). Desinstitucionalização. São Paulo: Hucitec, 1990. p. 17-59.

SARACENO, B. Libertando identidades: Da reabilitação psicossocial à cidadania possível. Belo Horizonte: Te Corá - Instituto Franco Basaglia, 1999. 176 p.

La ciudadanía como forma de tolerancia. Ginebra: Organización Mundial de la Salud, s.d. 20 p. (mimeo.)

SPINOZA, B. Ética. Belo Horizonte: Autêntica, 2009. 240p.

Recebido para publicação em Maio/2012

Versão definitiva em Agosto/2012

Suporte financeiro: não houve

Conflito de interesse: inexistente 